\title{
CARLOS NELSON COUTINHO: UM INTÉRPRETE MARXISTA E DEMOCRATA DA REALIDADE BRASILEIRA \\ ENTREVISTA COM IVETE SIMIONATTO
}

A Revista Em Tese, por ocasião do falecimento do intelectual marxista Carlos Nelson Coutinho no último dia 20 de setembro de 2012, apresenta, nesta edição, uma entrevista realizada com a Professora do Departamento de Serviço Social da UFSC Ivete Simionatto. A contribuição de Coutinho para o pensamento marxista brasileiro, o debate sobre a relação Socialismo e Democracia, o papel do intelectual orgânico na conjuntura política nacional foram alguns dos temas abordados. Ivete Simionatto foi orientanda de Coutinho durante sua tese de doutoramento na Pontifícia Universidade Católica de São Paulo no final dos anos 1980 e início dos 1990.

Carlos Nelson Coutinho, filósofo e cientista político especializado no pensamento de György Lukács e de Antônio Gramsci, teve um destacado papel na coordenação e editoração das obras do autor italiano no Brasil. É autor de artigos e de livros fundamentais de teoria política como "A Democracia como Valor Universal", "Ler Gramsci - Entender a Realidade" e "De Rousseau a Gramsci - Ensaios de Teoria Política".

Em Tese: Como a professora avalia o papel intelectual de Carlos Nelson Coutinho no pensamento marxista brasileiro?

Ivete Simionatto: Começo por uma frase de Carlos Nelson Coutinho com a qual ele gostava de se caracterizar: "um marxista convicto e confesso". Frase lapidar, utilizada por ele em toda sua produção. Produção toda atrelada ao marxismo, pela qual gostaria de adentrar ao assunto. Foram treze livros publicados, dezenas de artigos, além de traduções de obras de Gyorgy Lukács e de Antônio Gramsci.

Aos 17 anos, Coutinho publicou seu primeiro texto sobre Lukács. Desde muito jovem, inseriu-se no debate marxista. Em conversas comigo, ele lembrava que a primeira leitura de Marx fora do "Manifesto Comunista". O pai dele tinha este livro em casa e leitura despertou a paixão pelo marxismo desde muito cedo. 
Ao longo dessas quatro últimas décadas, toda a produção de Carlos Nelson Coutinho e todos os embates intelectuais e políticos que empreendera guardaram vínculos com o marxismo. Sem nenhuma dubiedade, ele nunca, no âmbito de sua discussão, teve qualquer vinculação com outra perspectiva teórica que não essa.

Eu acho que da grande contribuição de sua trajetória, a primeira que se destaca está na utilização do pensamento de Lukács para interpretar a realidade brasileira. Ele apropria-se do método de pensamento lukacsiano em uma modulação com o pensamento brasileiro. Carlos Nelson é um pioneiro na introdução do pensamento de Lukács no Brasil. Sei que houve outras leituras anteriores no país. Mas, Carlos Nelson vai se apropriar de Lukács de maneira extremamente propositiva e original, ao analisar a literatura e a realidade brasileira. Questões importantes são arregimentadas por ele em seus trabalhos de crítica literária da década de 1960 e 1970, com destaque para o livro "Literatura e Humanismo". Nesse livro, aborda o pensamento de Graciliano Ramos, Proust, Kafka e Lima Barreto. Ele resgata as questões de cultura, do nacional popular e da literatura brasileira, apontando como a nossa cultura viveu, em muitos períodos da nossa história, o que ele chama na obra de "intimismo à sombra do poder" - utilizando uma expressão de Thomas Man.

Mais tarde, ele publica "Cultura e Sociedade no Brasil", uma coletânea que novamente reflete a literatura brasileira com o arcabouço teórico lukacsiano. O livro recebeu várias republicações. Em 1971, publica "O Estruturalismo e a miséria da razão", em que realiza um grande debate sobre a ontologia de Lukács e as bases estruturalistas.

Outro marco importante, que depois será o norte da formação e da produção de Carlos Nelson Coutinho, é a ligação ao pensamento de Gramsci. Isso começa nos anos 1960, quando, através do esforço da Editora Civilização Brasileira, Ênio Silveira - então na direção da entidade e com contatos com o Instituto Gramsci - convida Carlos Nelson Coutinho, Leandro Konder e Luiz Mario Gazzaneo para a tradução dos primeiros volumes dos "Cadernos do Cárcere". Aquela tradução temática que todos conhecem. O trabalho teve início com as "Cartas do Cárcere", depois "A Concepção Dialética de História", "Intelectuais e a Organização da Cultura". Foram vários volumes traduzidos por ele, até que o trabalho é interrompido em 1968, por causa do Al-5. A tradução é retomada somente depois, em meados dos anos 1970.

Um novo projeto de tradução da obra de Gramsci, do qual Carlos Nelson é o idealizador, começa em 1999 e termina em 2005, com a publicação de seis volumes dos "Cadernos do Cárcere", uma tradução nova que busca reintegralizar os "Cadernos". Os textos 
são apresentados na ordem cronológica da escrita de Gramsci e traz alguns elementos analíticos novos, a partir das indicações de Gianni Francioni.

Eu considero essa publicação brasileira um marco na história do pensamento de Gramsci no Brasil, que supera a edição anterior. Não que a edição togliatiana esteja datada, mas eu considero essa nova edição que Carlos Nelson assumiu e realizou no Brasil um marco do pensamento marxista e do pensamento de Gramsci.

A aproximação maior a Gramsci aconteceu quando Carlos Nelson foi para Itália, exilado em 1971. Permanece um período em Bologna - um grande centro cultural e político na Itália - e depois passa uma pequena temporada em Paris. Acompanha a discussão do Eurocomunismo, principalmente a realizada por Pietro Ingrao, no eixo da "democracia de massas".

Quando voltou para o Brasil, publicou aquele polêmico artigo "A Democracia como Valor Universal", de forte vinculação com o debate da esquerda italiana. Mas, antes de tudo, esse artigo foi uma grande contribuição. Primeiro, pela provocação à esquerda; e segundo, porque ele mesmo se penitenciava dizendo "eu deveria ter usado democracia como valor que vai se universalizando" e não "democracia como valor universal", porque para os liberais o jargão serviu como uma luva e na esquerda gerou grandes críticas.

No marxismo, a tese [do artigo] sempre foi defendida por Carlos Nelson Coutinho: "[...] não há democracia sem socialismo, não há socialismo sem democracia". Avalio que "A democracia como valor universal" trouxe uma discussão extremamente importante para compreender como otimizar as conquistas da classe trabalhadora que são efetivadas no transcorrer da sociedade capitalista burguesa e como tais conquistas podem ser potencializadas em outro projeto de sociedade. Ele já fez várias reinterpretações desse texto. Na última que realizou, disse que, em toda busca de construção do socialismo, é impensável o socialismo sem democracia. Essa consideração traduzia o embate que ele teve contra o socialismo real. Pois este socialismo permeou muito a esquerda brasileira nos anos 1960 e trouxe uma concepção nefasta na construção (da luta pelo) do socialismo, na luta por outro tipo de sociedade no Brasil.

Então, considero que a permanência de Carlos Nelson na Itália fez com que ele se aproximasse mais do pensamento gramsciano, o que influencia sua produção subsequente. Penso que ele nunca deixou de ser lukacsiano. No entanto, acho que passou o tempo em que se dizia "Gramsci ou Lukács". Carlos Nelson Coutinho sempre defendeu Gramsci e Lukács. E, no âmbito do marxismo, sempre apontou os problemas que ele percebia na obra de Lukács, como a ausência de discussão sobre a política; e os problemas que ele notava na obra de Gramsci, a 
ausência da discussão sobre o trabalho enquanto esfera ontológica do ser social. No último livro dele, "De Rousseau a Gramsci", há um belo texto de José Paulo Netto que resgata esta discussão de Gramsci e Lukács. Um vácuo que havia nesse debate.

Uma das vezes em que ele estava discutindo suas ideias marxistas na UFRJ, veio à tona "Democracia como Valor Universal". E um doutorando perguntou a ele: "o senhor é um socialdemocrata ou um socialista?". E ele olhou com a calma que the caracterizava e disse: "eu não sou uma coisa nem outra, eu sou um comunista". Esse era Carlos Nelson Coutinho.

Da mesma maneira que Mariategui introduziu Gramsci na América Latina, essa tarefa no Brasil coube a Carlos Nelson Coutinho. E sua obra é um patrimônio para pensarmos a realidade do país a partir de um eixo de discussão extremamente profícuo - o pensamento de Gramsci. A obra de Coutinho não é marcada por conceitos literais, estando sempre vinculada à interpretação da realidade brasileira. O elo que ele estabeleceu com os autores marxistas resultou nesse grande legado. Inclusive ele colaborou na tradução da coleção organizada por Eric Hobsbawm sobre "A História do Marxismo".

Em Tese: Diante do projeto político que permeou os debates intelectuais da esquerda, como Carlos Nelson Coutinho pensou a revolução para o comunismo no Brasil? Como ele trabalhou conceitualmente o projeto de ruptura ao processo político brasileiro, projeto tão característico das visões trotskistas, leninistas, stalinistas e também de diferentes setores da academia?

Ivete Simionatto: A militância de Carlos Nelson Coutinho começa no movimento estudantil. Nos anos 1960, ele sai da Bahia e vai ao Rio de Janeiro, quando se vincula ao PCB. Só que na análise da esquerda brasileira, havia a ideia de que o Brasil era uma sociedade atrasada, oriental, de capitalismo débil, pouco desenvolvido. Carlos Nelson, por sua vez, fazia uma análise diferenciada. Ele dizia que o capitalismo monopolista de Estado era efetivo na realidade brasileira. Havia também a entrada do capital internacional, em um processo amplo do desenvolvimento do capitalismo, mesmo sob a Ditadura Militar. Além disso, ele observava uma forte correlação da política com o desenvolvimento organizativo da sociedade civil. As categorias "Oriente/ Ocidente" de Gramsci servem justamente para mostrar que há sociedades com traços orientais, atrasados, de capitalismo ainda primitivo, mas onde coexistem traços de ocidentalidade, de socialização da política, de participação das camadas de classe no contexto da sociedade. 
Carlos Nelson enfrentava esse debate junto ao PCB. Advogava que a opção por uma revolução armada, de um golpe, de derrubada do poder, não era possível. A realidade brasileira mostra que tanto o Estado tinha um poder coercitivo muito grande, como também nós tínhamos uma robusta sociedade civil. E nesse processo de correlação de forças, a revolução armada não teria mais espaço. Era preciso pensar no processo de transição socialista. Para isso, ele vai utilizar a categoria "guerra de posição" de Gramsci.

Portanto, esse embate com a esquerda sempre foi muito forte. Ele vai para Itália, não rompe com o PCB e continua escrevendo para o jornal "Voz da Unidade". Na volta, ele continua esse embate. Ele mostra que a estratégia de luta da esquerda, vinculada a uma visão trotskista e, mais tarde, à visão do PSTU, não cabia à realidade brasileira. E, dentro do movimento do $\mathrm{PCB}$, ele teve um distanciamento político cada vez maior, contrário às estratégias de luta defendidas pelo partido.

Depois de um tempo, com a criação do PT, ele sai do PCB para se filiar ao novo partido. E nessa relação com a política, ele atuou muito junto ao PT como "intelectual orgânico". Carlos Nelson Coutinho é um exemplo de "intelectual orgânico" junto aos partidos e aos movimentos sociais.

E ele sempre defendeu a perspectiva de um reformismo revolucionário. Isso ele nunca escondeu, está presente na obra dele. É a ideia de "guerra de posição" gramsciana. Ou seja, as conquistas progressivas - características de sociedades em que o capitalismo vai se desenvolvendo - desencadeiam, simultaneamente, um amplo processo de socialização da participação política. As conquistas progressivas que um dia possam romper com a ordem burguesa e se chocar com a ordem do capital são traduzidas por ele pela concepção gramsciana de "guerra de posição", e não mais por guerra de movimento e revolução armada, como grande parte da esquerda ainda defendia naquele momento.

E, durante um grande período, as teses dos Congressos do PT encamparam as ideias de um reformismo revolucionário, de disputa pela hegemonia e do papel do intelectual orgânico. Demonstram isso, principalmente, as teses dos anos 1980. E Carlos Nelson defendeu sempre essa posição.

Tanto que boa parte das análises de interpretação da realidade brasileira feita por Carlos Nelson compreende uma teoria do Brasil contemporâneo. Ele trabalha desde os anos 1930 até os anos atuais, discutindo nosso processo de revolução passiva, de revolução pelo alto, nosso processo de transformação da política e as formas de organização da sociedade civil. Portanto, recorrentemente na análise da realidade brasileira, Carlos Nelson parte do 
pensamento de Gramsci. Ele confrontava as teses althusserianas, trotskystas, leninistas - várias delas - a uma defesa sempre intransigente que a nossa realidade tinha muitas características similares as que Gramsci tinha analisado no Risorgimento italiano, na unificação daquele Estado, e que cabiam também, muitas delas, para pensar os meandros da realidade brasileira.

Quando o PT chegou ao governo, na eleição de Lula, Coutinho esperou um determinado momento o direcionamento do partido. E ficou muito desgostoso com os rumos que o partido tomou. Eu me lembro de um dia em que agendamos um encontro no Rio e ele desmarcou indicando que iria encontrar um grupo do PT. E a pergunta que ele tinha era a seguinte: "antes das eleições vocês apontaram um caminho; vocês chegaram ao poder e dentro do poder vocês perceberam que havia dois caminhos. E vocês tomaram um caminho e não indicam onde esse caminho vai dar. Se vocês não sabem onde esse caminho vai dar, eu estou fora do PT". E foi assim que ele rompeu com o PT. Ajudou a fundar o PSOL e se vinculou ao novo partido.

E, nesse período, ele sempre colocou as discordâncias que tinha ao PSTU e a Álvaro Bianchi, um dos militantes deste partido. Os dois tinham uma relação intelectual muito respeitosa. Carlos Nelson sempre dizia que havia de chegar um momento em que a esquerda precisaria de uma postura coletiva, conjunta, senão não iríamos construir o momento éticopolítico como Gramsci havia colocado.

Então, mesmo com as diferenças existentes na esquerda, ele sempre as respeitou e militou dentro dela, na perspectiva de construção de alianças. Nesse aspecto, ele sempre esteve calcado na realidade, por mais que o método histórico-dialético tenha o ajudado a interpretar as possíveis estratégias e táticas que a esquerda pode ter em determinadas conjunturas. Acho que essa é uma riqueza grande que ele traz para a interpretação da realidade brasileira via pensamento de Gramsci e via também a participação na militância política.

Em Tese: Seguindo o conceito de intelectual orgânico, qual a atuação de Carlos Nelson Coutinho na relação academia e movimentos sociais?

Ivete Simionatto: Carlos Nelson chegou à academia muito tarde. Ele entrou na universidade em 1986. Logo, ele não é um professor acadêmico como concebemos. Embora, se ele fizesse o Lattes naquele momento, já estaria ali registrada uma grande produção. Nesse sentido, ele foi, concomitantemente, um intelectual orgânico e um intelectual tradicional. E mesmo estando na 
academia, ele nunca se desvinculou da militância política. Ademais, a relação com o MST foi mais próxima ainda porque foi criada no Rio de Janeiro, na UFRJ, a Escola Florestan Fernandes, a escola de formação do MST. Carlos Nelson é um dos fundadores e sempre deu aulas lá. Tanto que no dia em que ele faleceu, em seu velório, fizeram homenagens o MST, a Via Campesina e os demais movimentos sociais. Todos estavam lá com suas bandeiras e foi muito bonito. Porque ele tinha uma proximidade muito grande a esses movimentos. A proximidade era direta, na discussão nos acampamentos, com as lideranças e com os intelectuais do MST. Ele nunca se distanciou dos movimentos sociais em nada do que ele pudesse contribuir.

Eu sempre digo que Carlos Nelson Coutinho era um permanente persuasor. Tanto na universidade quanto nos movimentos sociais, ele nunca se negou a estar presente em qualquer debate. Aparecia um sindicato na periferia de São Paulo, ele ia, por ser considerado importante nesse processo de formação política. Acho que ele teve muito de Gramsci nessa vinculação direta com as camadas subalternas. Sempre no horizonte desse processo de formação política.

Por sua vez, as aulas de Carlos Nelson tinham uma profundidade teórica, filosófica, metodológica. Mas, mais do que tudo, ele deu uma contribuição para a formação de várias gerações nas áreas da Educação, Serviço Social, Ciência Política e Filosofia, no sentido de criar uma consciência crítica, de pensar uma sociedade de maneira diferente e fazer da universidade um aparelho de hegemonia com a possibilidade de pensar outro tipo de cultura que não essa cultura dominante. Ele teve um perfil muito diferente do que hoje a academia quer requisitar, perfil este vinculado a processos burocráticos. Ele nunca foi esse tipo de professor.

Uma das últimas atividades dele foi como editor da editora da UFRJ, na qual ele deu uma contribuição imensa na publicação de inúmeras obras no campo do marxismo, mudando a perspectiva editorial. Deixou mais um legado com a publicação de obras que tematizam os movimentos sociais, de trabalhos sobre as relações de opressão contra a classe trabalhadora e também de pensadores marxistas.

Essa inserção foi muito presente em todos os momentos da vida dele. Eu até me lembro das vezes em que ele ligava e dizia "olha, convidaram-me para fazer uma fala no interior da Bahia em um Movimento Social e eu não posso ir. Você pode me substituir?". Ele ia ou procurava alguém. Ele nunca deixava um vácuo quando convidado. Essa era uma grande característica dele, o compromisso que teve com a construção do que ele chamava de "sociedade democrática e socialista".

Em Tese: A professora já tratou do reformismo socialista de Carlos Nelson Coutinho, então 
podemos avançar e dizer que ele era a favor da frente popular, uma estratégia que o PCB defendeu em várias circunstâncias...

Ivete Simionatto: É, nesse ponto, sim. Quando ele defende a estratégia gramsciana de "guerra de posição", penso que a construção de uma frente popular composta pelas forças da sociedade civil defensoras do mesmo projeto de sociedade coloca-se nessa direção. A construção de alianças sugerida por Gramsci também aparece aqui, como por exemplo, quando defendeu essa estratégia para a superação do fascismo na Itália no final dos anos 1920.

Em Tese: Porque Caio Prado Júnior, por exemplo, não defendia a frente popular...

Ivete Simionatto: A análise que Coutinho faz da obra de Caio Prado é na sua contribuição ao desvendamento do capitalismo brasileiro através de um processo dito "não clássico" e reconhece em Caio Prado sua grande contribuição analítica do Brasil a partir do marxismo o que o aproximaria da perspectiva leninista de "via prussiana" ou de "revolução passiva"de Gramsci. Nessa questão sobre a frente popular, penso que Coutinho se aproxima mais da proposta de democracia de massa de Pietro Ingrao, mas não vejo nele uma discordância sobre necessidade de uma a frente popular das forças de esquerda como estratégia para a construção do socialismo.

Em Tese: Como a professora interpreta o "pensar a democracia para o socialismo" de Carlos Nelson no cenário político contemporâneo? Especificamente agora que tivemos eleições e mesmo diante dos embates contemporâneos de duas forças políticas do país, uma social democracia mais a direita, e a outra uma social democracia trabalhista - vamos sintetizar assim. Quais seriam as possíveis alternativas, quais as leituras recentes de Carlos Nelson para esse cenário presente do Brasil?

Ivete Simionatto: Um dos textos que Carlos Nelson escreveu sobre a conjuntura atual está publicado no livro "Hegemonia às Avessas: economia, política e cultura na era da servidão financeira", organizado por Rui Braga, Francisco de Oliveira e Cibele Rizek. E ele analisa a conjuntura contemporânea ao tratar nossa realidade como a da "pequena política", uma categoria gramsciana.

Nesse mesmo texto, há uma defesa de Chico de Oliveira de que o Brasil vive uma 
hegemonia às avessas; e de Álvaro Bianchi ao afirmar que vivemos um processo de "revolução passiva". Por sua vez, Carlos Nelson vai se posicionar totalmente diferente, ao indicar que dentro da conjuntura em que vivemos, ao modo como as políticas estão colocadas, temos uma proposta de governo que reduz em grande medida os direitos conquistados num processo de "revolução passiva". Como ele analisa em outros terrenos da história brasileira e tomando a categoria gramsciana, as "revoluções passivas" indicam que, em certa medida, o Estado traz para dentro de si ou responde a várias demandas legítimas da classe trabalhadora. Ao passo que, em períodos de "pequena política", vivemos em processos de contrarreforma e, portanto, de regressão de direitos, de regressão de conquistas da classe trabalhadora. O governo atual, tanto o de Lula quanto o de Dilma, caminha dentro dessa perspectiva, onde há espaço apenas para ações pontuais.

No campo democrático, Carlos Nelson mostra a dificuldade que se tem de avançar na articulação de sujeitos políticos coletivos, pelo próprio processo de transformismo e cooptação efetivado pelo governo. Isso lembrando o processo de cooptação pelo governo da CUT e de uma parte do MST. Coutinho utiliza várias categorias gramscianas para explicar o fenômeno. Ou seja, a dificuldade que a cultura política brasileira impõe para termos, nesses últimos anos, uma frente única, uma frente popular, para construir um projeto da esquerda dada essas formas de desmobilização dos movimentos sociais advindos não só da forma de organização da política, mas também por conta de toda a conjuntura internacional que vivemos e da qual o Brasil não está isento.

Por outro lado, Coutinho sempre defendeu a possibilidade de construção de alianças da esquerda para confrontar o projeto capitalista construído na realidade brasileira. Sempre com as suas ressalvas, de que a esquerda não pode fazer aliança com deus e com o diabo, ele analisa quais as alianças que a esquerda pode construir para vislumbrar em um futuro o rompimento com esse tipo de sociedade que vivemos. É o "pessimismo da inteligência e o otimismo da vontade", mostrando que a conjuntura é muito desfavorável para a classe trabalhadora.

Temos uma dificuldade cada vez maior, no Brasil e no mundo, para a articulação da classe trabalhadora, que vem atravessada por todas essas questões de cooptação, de favores, de regressão de direitos. Os integrantes do MST, por exemplo, nas analises que os próprios militantes fizeram, aderem ao [Programa] Bolsa família. Por quê? Porque os militantes não tem como sobreviver. São questões de sobrevivência que a classe trabalhadora não fica imune. Isso não justifica, por exemplo, que, em momentos de grande liberdade, até [João Pedro] Stédile 
posicione-se ora no confronto ao governo, ora no apoio. Porque a conjuntura brasileira, com o PT no poder, sempre foi a possibilidade de se transformar isso por dentro. Isso se colocava como um horizonte, mas foi se perdendo na medida em que as alianças políticas dentro do governo ocorreram nas formas mais esdrúxulas possíveis.

Os grandes intelectuais da esquerda começaram a se afastar disso, como Chico de Oliveira e outros que romperam com o governo. A emergência do PSOL apresentou-se como umas das alternativas, como uma das possibilidades, mas com toda a fragilidade que se tem de constituição de um processo de ruptura com um modelo de sociedade que está posto. Por exemplo, ele apoiou a candidatura de Marcelo Freixo à prefeitura do Rio de Janeiro, um momento de possibilidade da esquerda de fazer alianças com outras tendências desse campo que, naquele momento, não se colocaram dispostas a fazer o rompimento com formas de cooptação que o governo realizou. É um processo muito complicado, muito difícil, uma conjuntura complexa a que vivemos. Carlos Nelson sempre repetiu suas crenças, mesmo com a dificuldade que temos em avançar no processo brasileiro. Defendeu sempre o fortalecimento dos movimentos sociais, das ideias da esquerda. Ele nunca cedeu em nada com o pensamento da esquerda que defendia.

Ao pensar a conjuntura brasileira hoje, acho que o debate dele sobre a democracia e a cidadania permanece fundamental, uma contribuição extremamente profícua para pensarmos de que maneira é possível rearticular a esquerda, rearticular os movimentos sociais e a classe trabalhadora, como um momento preparatório pra se chegar à luta mais avançada, de busca de autonomia e emancipação.

Em Tese: Dentro do capitalismo contemporâneo, quem é, para Carlos Nelson Coutinho, o sujeito histórico de transformação?

Ivete Simionatto: Carlos Nelson Coutinho nunca deixou dúvidas: em toda a obra dele o sujeito histórico, o sujeito político, é o partido político. Ele sempre colocou isso, o sujeito histórico capaz de universalizar as demandas da classe trabalhadora é o partido. Ele nunca abdicou dessa ideia, mesmo nos momentos em que vivemos, de ebulição mundial, de Fórum Social Mundial, de podermos encontrar um espaço de universalização de demandas. Esse foi um momento em que esse debate proliferou, até em algumas tendências da pós-modernidade, como nas propostas de Boaventura de Souza Santos. Só que Carlos Nelson nunca abdicou de que o sujeito histórico por excelência é o partido político. Tanto que ele sempre foi militante de 
partido político. Sempre disse que num partido político ele entra pela porta da frente e sai pela porta da frente. Ele sempre ficou nos partidos políticos até o momento em que podia defender as ideias que considerava profícuas de uma esquerda democrática e propositiva. Ele nunca abdicou de ser representante coletivo da classe trabalhadora num partido político.

Em Tese: Se estivermos certos nas nossas leituras, os movimentos sociais tendem a se separar desse potencial de universalização que os partidos políticos detinham...

Ivete Simionatto: Exatamente, tem que recuperar o papel do partido político, recuperar o elo dos partidos junto aos movimentos sociais. Carlos Nelson é muito fiel ao conceito de Sociedade Civil de Gramsci, o de buscar essa grande movimentação da sociedade civil tentando unificar as instituições organizativas da classe trabalhadora. Esta discussão está presente no conceito de sociedade civil de Gramsci e apropriado por Carlos Nelson Coutinho. Não essa sociedade civil amorfa do terceiro setor, mas uma sociedade civil que abarca diferentes institutos coletivos da classe trabalhadora que confluem para os partidos políticos. Portanto, ele sempre defendeu isso em toda a sua obra, essa proposição. Por isso, ele sempre esteve vinculado a um partido.

Em Tese: $\mathrm{Na}$ atual crise internacional, movimentos apartidários e massivos são responsáveis pela Primavera Árabe e grandes manifestações na Grécia e na Espanha. A esquerda e a direita, como se consolidaram nesses países, são diuturnamente questionados. Em uma leitura a partir de Carlos Nelson Coutinho, seria um momento, uma oportunidade histórica para novos partidos como sujeitos coletivos?

Ivete Simionatto: Eu nunca ouvi nenhuma fala de Carlos Nelson sobre isso. O que eu acho, o que conheço da posição dele, é que esses movimentos massivos tomam importância conjuntural que podem provocar o surgimento de novas forças aglutinadoras de ideias, mas não como movimentos espontâneos. Acho que essa ideia de movimento massivo que vem sem direção tem um pouco de espontaneismo. E na obra de Carlos Nelson há sempre uma crítica à visão espontaneista. Em vários momentos ele defende Rosa Luxemburgo, mas em outros ele critica a visão espontaneista que ela fazia dos movimentos de massa. Carlos Nelson sempre defendeu a ideia de uma esquerda organizada. Não há movimento desorganizado que possa assumir, concretamente, uma direção política mais ampla sem um espaço de unificação $E$ os movimentos desorganizados são movimentos espontâneos, que às vezes não tem direção. A 
direção política ocorre na medida em que há uma organização e essa grande organicidade ocorre no partido político. Isso está presente em todas as reflexões que ele faz da política. Um texto dele, que está no livro "Ler Gramsci e entender a realidade", indica que toda discussão e organização da política acontece nos institutos coletivos da classe trabalhadora, que são muitos, mas que se unificam no partido político.

Em Tese: A professora tratou várias qualidades e características do professor e militante Carlos Nelson Coutinho. Nós queremos que a senhora exponha como era a pessoa Carlos Nelson, no trato, na amizade, no carisma junto às pessoas que o circundavam.

Ivete Simionatto: Carlos Nelson foi uma figura extremamente generosa, coerente, amável. Eu conheci Carlos Nelson pessoalmente em 1988, quando ele começou a orientar a minha tese de doutorado na PUC-SP. Ele era professor da UFRJ. Antes a Capes permitia esse trânsito e eu já conhecia alguns de seus textos. Fui apresentada a ele por um professor de nossa área, José Paulo Netto. Lembro-me que fui ao Rio de Janeiro conversar com ele e vi aquele homem alto, imenso e extremamente generoso e respeitoso.

Uma grande qualidade que considero ao pensar em Carlos Nelson é o respeito pelo adversário. Ele sempre se colocou em relação ao adversário no debate das ideias de forma respeitosa. Nunca o vi desqualificando alguém, nem de forma pública, nem de forma pessoal. Ele nunca foi agressivo ou se colocou de uma maneira ofensiva frente às pessoas que pensavam de maneira diferente da dele. Ele sempre defendeu o pluralismo. Por isso sua obra foi e é pública. Tudo o que escreveu, ele socializou. Ele queria que suas ideias fossem socializadas e discutidas.

Era uma pessoa que ficava horas conversando sobre determinado tema, uma pessoa muito leve, muito agradável, muito humana. Jamais negava algo que estivesse ao seu alcance. Uma pessoa de uma generosidade imensa. Acho que além do vazio intelectual, ele deixa um vazio humano muito grande pela relação que tinha com todas as pessoas que convivia. Uma pessoa que tinha uma paixão enorme pela atividade que exercia, tanto pela de militante como pela atividade de ensinar. Sobretudo, ele nunca abdicou de suas ideias, nunca se deixou seduzir por modismos acadêmicos. Ele sempre foi fiel às ideias comunistas que defendia. Foi um grande exemplo de intelectual, muito raro de se encontrar hoje, principalmente na academia diante da competitividade que vivemos. 